\title{
Calcium Signaling, Calcineurin and NFAT3 Molecular Pathway in Reprogramming of Fetal Gene (BNP) Expression in Cardiac Hypertrophy and Inhibitors of Cardiac Hypertrophy-Review
}

\author{
Kousalya.P $\mathbf{P}^{1,2^{*}}$ and Doss $\mathrm{VA}^{3}$ \\ ${ }^{1}$ Research Scholar, Department of Biochemistry, PSG College of Arts \& Science, \\ Coimbatore-641014, Tamilnadu, India. \\ ${ }^{2}$ Assistant Professor, PG and Research Department of Biochemistry, Bharathidasan \\ College of Arts and Science, Erode-638116, Tamilnadu, India. \\ ${ }^{3}$ Associate Professor, Department of Biochemistry, PSG College of Arts and Science, \\ Coimbatore-641014, Taminadu, India. \\ ${ }^{1,2}$ kousiviswa@gmail.com, ${ }^{3}$ victordoss64@gmail.com
}

*Corresponding Author: Kousalya.P- Research Scholar, Department of Biochemistry, PSG College of Arts \& Science, Coimbatore-641014, Tamilnadu, India.Email-Id: kousiviswa@ gmail.com

\begin{abstract}
G-Protein Coupled Receptor (GPCR) plays a major role in cardiac hypertrophy. Isoproterenol is an agonist which binds to GPCR. This results in the activation of GS subunit. Activated Gs subunit stimulates cAMP mediated pathway. This activates the calcium signaling and elevates the calcium level. Increased calcium activates the phosphatase activity of calcineurin. Activated calcineurin dephosphorylates NFAT in cytoplasm. Dephosphorylated NFAT translocates to nucleus and binds to target region in DNA and activates re-expression of fetal genes in synergy with GATA-4 trascription factor. Reprogramming of fetal genes by NFAT3 and GATA-4 results in cardiac hypertrophy. Calcineurin inhibitors and rephosphorylation of NFAT can prevent cardiac hypertrophy.
\end{abstract}

Key Words: Calcium signaling, Cardiac hypertrophy, Isoproterenol, Calcineurin, NFAT, B-type natriuretic peptide (BNP).

\section{Introduction}

The heart consists of cardiac myocytes, non-myocytes and the extracellular matrix surrounding them. Cardiac myocytes are the muscle cells of the heart such as fibroblast, mast cells, endothelial cells and smooth muscle cells ${ }^{[1]}$. Cardiac hypertrophy is a response that is adaptive to pressure overload, volume stress and sarcomeric protein mutation. Many types of heart disease are characterized by hypertrophic development especially hypertension, ischemic disease, valvular disease and heart failure ${ }^{[2-4]}$. Cardiomyocyte hypertrophy is associated with a significant increase in size of the cell, elevated protein synthesis and expanded sarcomere organization at cellular level ${ }^{[5]}$. 


\section{Physiological and Pathological Cardiac Hypertrophy}

Cardiac hypertrophy is classified as physiological cardiac hypertrophy and pathological cardiac hypertrophy (Figure-1). Pathological cardiac hypertrophy is accompanied by disease like hypertension. It is the major risk factor for the failure of the heart ${ }^{[6]}$. Elevated interstitial fibrosis cardiac dysfunction and cell death are correlated with pathological hypertrophy ${ }^{[6]}$. Physiological cardiac hypertrophy is due to prolonged exercise. It is defined by normal morphology of heart. There is no fibrosis and apoptosis of cells. In physiological cardiac hypertrophy cardiac function is increased or normal ${ }^{[6]}$.

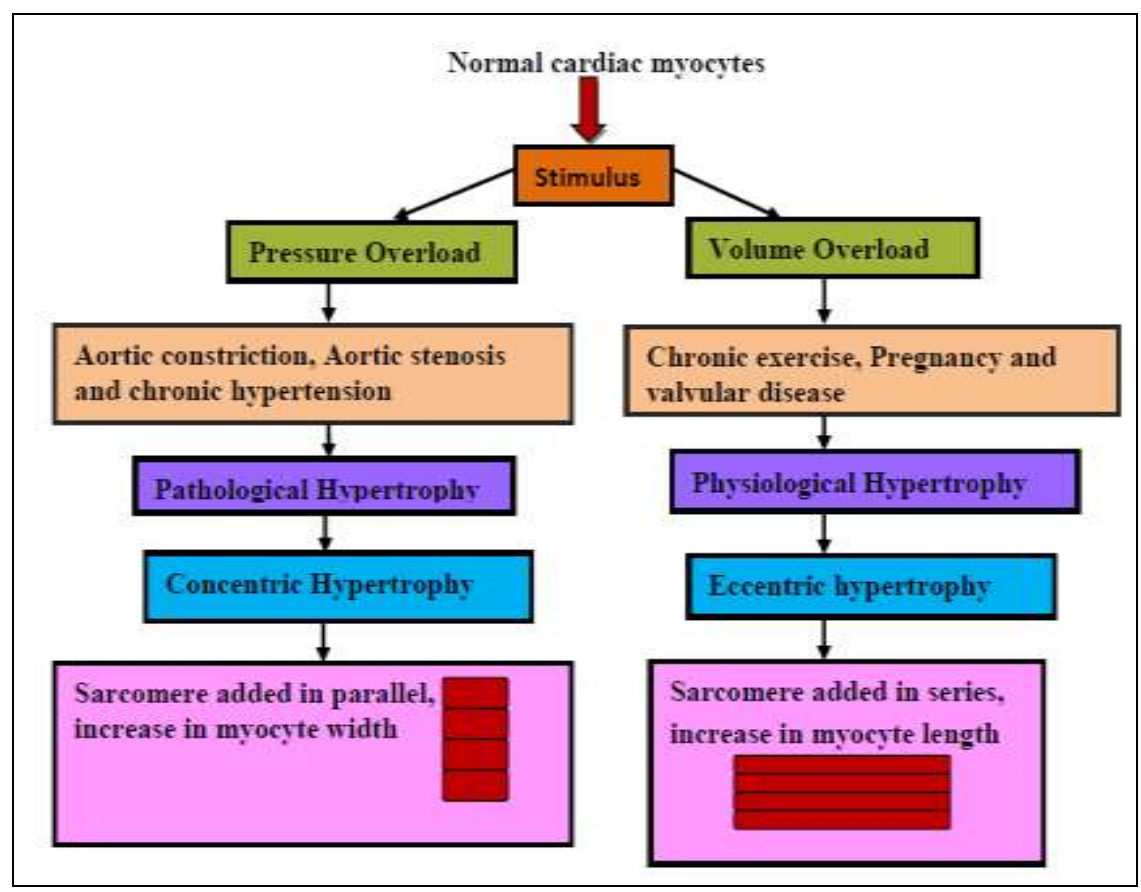

Figure-1: Physiological and Pathological Cardiac Hypertrophy

Physiological and pathological hypertrophy is categorized as concentric and eccentric hypertrophy. This classification is based on shape changes ${ }^{[5]}$. Prolonged left ventricular pressure overload due to pathological stimuli primarily induces thickening of wall and concentric hypertrophy. In concentric hypertrophy addition of sarcomere in parallel contributes to an increase in the width of myocyte cells ${ }^{[6]}$. Prolonged left ventricular volume overload due to physiological stimuli results in enlargement of chamber and an eccentric hypertrophy ${ }^{(4)}$. In eccentric hypertrophy addition of sarcomere in series contributes to an increase in the length of myocyte cells and increased volume in the chamber ${ }^{[6]}$.

\section{Cardiac Energy Metabolism for Normal Heart and Hypertrophised Heart}

The distortion of the metabolism of the cardiac energy substrate plays a crucial role in failure of the heart. In normal heart fatty acid is the primary metabolic pathway which gives highest energy. In pathological condition glucose is utilized as a primary substrate for metabolism to produce energy ${ }^{[7]}$. 


\section{Calcium Signaling in Cardiac Hypertrophy}

Calcium is an important second messenger ${ }^{[8]}$. Calcium plays an essential role in the regulation of heart contractility, fertilization, growth, differentiation and gene expression ${ }^{[9,10]}$. Hypertrophic cardiac development and cardiac failure are triggered by calcium ${ }^{[9]}$. Calcium level in the cells are elevated by the $\operatorname{stimuli}^{[10]}$. Calcium regulates the cellular activities through calmodulin, a calcium binding protein ${ }^{[11]}$. Increased expression of calmodulin cause cardiomyocyte hypertrophy ${ }^{[12]}$. Increased calcium via calmodulin stimulates the calcineurin activity $^{[13]}$.

\section{Activation of G-Protein Coupled Receptors (GPCR) by Isoproterenol}

G-protein coupled receptor is made up of a seven transmembrane $\alpha$-helix structure. Adrenergic receptors are major class of G-protein coupled receptors (GPCR) ${ }^{[14,15]}$. There are three subtypes of $\beta$-Adrenergic receptors are present, they are $\beta 1-A R, \beta 2-A R$ and $\beta 3$-AR. Among these adrenergic receptors, $\beta 1$ adrenergic receptor $(80 \%)$ is the predominant type found in cardiac ${ }^{[14-16]}$. Stimulation or increased expression of Gas coupled $\beta 1$-AR by agonist cause cardiac hypertrophy ${ }^{[17-19]}$.

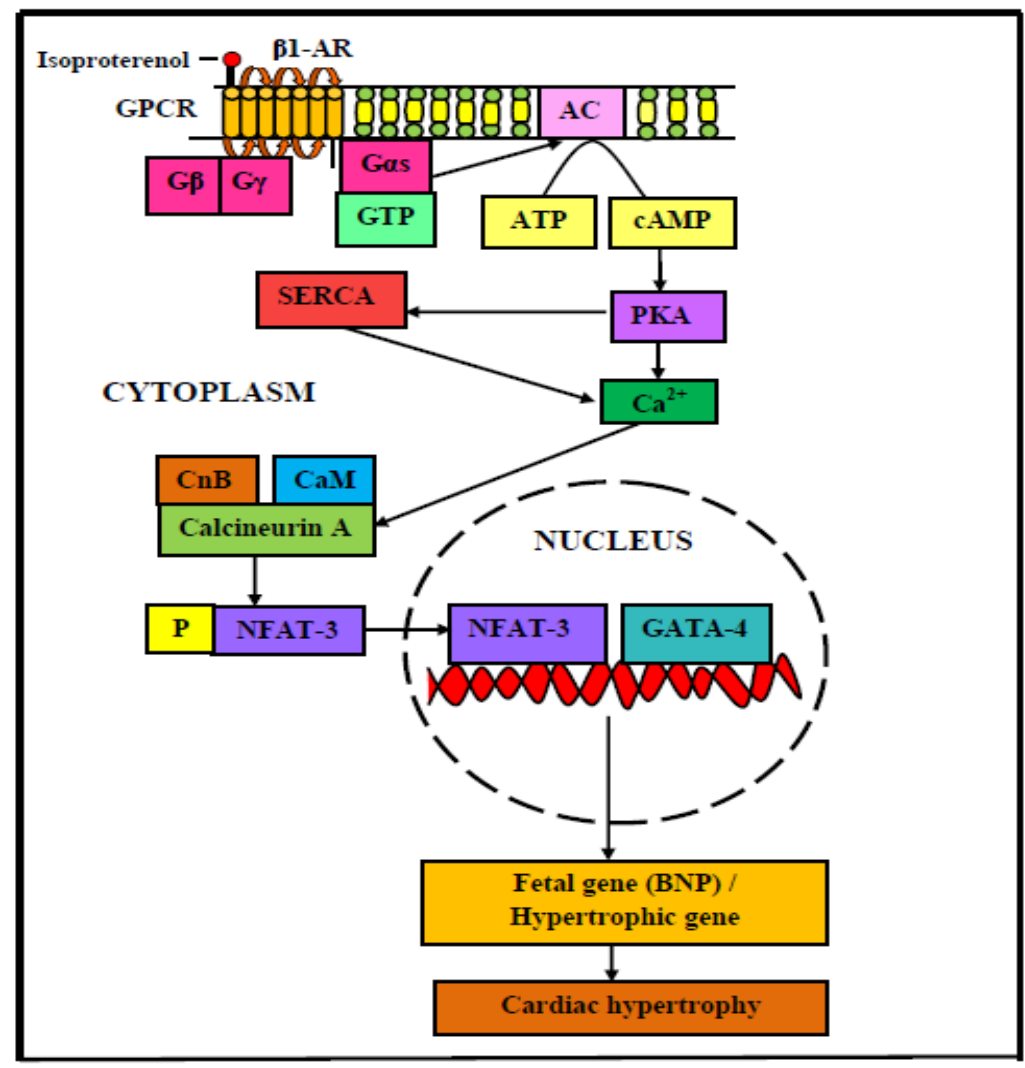

Figure-2: Molecular mechanism of cardiac hypertrophy. NFAT-3-Nuclear Factor of Activated T cell, PKA-Protein Kinase A, CnB-CalcineurinB, AC-adenylyl cyclase, CaMCadmodulin, GATA-4-transcription factor, SERCA- Sarco-Enoplasmic Reticulum $\mathrm{Ca}^{2+}$ ATPase and B-type natriuretic peptide (BNP). 
Isoproterenol is an agonist for $\beta 1-\mathrm{AR}$. Binding of isoproterenol to Gs coupled $\beta 1-\mathrm{AR}$ induce cardiac hypertrophy through Gas-cAMP mediated signaling pathway ${ }^{[17,20-22]}$. Binding of isoproterenol to Gas coupled $\beta 1-\mathrm{AR}$ stimulates the adenylyl cyclase (AC). Activated adenylyl cycle stimulate the formation of second messenger cAMP from ATP. This cAMP activates the protein kinase A (PKA). Activated PKA phosphorylares membrane ion channels and increase the $\mathrm{Ca} 2+$ cycling. Increased calcium stimulates the calcineurin activity through calmodulin. Activated calcineurin dephosphorylates the NFAT in cytosol (Figure-2). Dephosphorylated NFAT enters the nucleus and activates transcription factors and results in cardiac hypertrophy ${ }^{[17,21,23-25]}$.

\section{Activation of Calcineurin and NFAT Molecular Pathway by Calcium Signalling}

Calcineurin, a serine threonine phosphatase which is also recognized as protein phosphatase 2B or PP2B which is foundin cytoplasm (Figure-3). Calcineurin is an enzyme complex which is regulated by calcium. Calcineurin is a heterodimer consists of two subunits calcineurin A $(\mathrm{CnA})-60 \mathrm{kDa}$ catalytic subunit and calcineurin $\mathrm{B}(\mathrm{CnB})-19 \mathrm{kDa}$ regulatory subunit ${ }^{[26-28]}$. Calcineurin $\mathrm{A}(\mathrm{CnA})$ has a catalytic domain, a domain for binding of calcineurin $\mathrm{B}(\mathrm{CnB})$, a domain for calmodulin $(\mathrm{CaM})$ binding and an auto inhibitory domain(AID) ${ }^{[27,29,30]}$. Calcineurin $\mathrm{A}$ is encoded by three distinct genes in mammals named as $\alpha, \beta$ and $\gamma$. Calcineurin $A \gamma$ is expressed in testis. Calcineurin $A \alpha$ and calcineurin $A \beta$ is expressed in heart (26). Calcineurin $\mathrm{B}(\mathrm{CnB})$ contains four conserved $\mathrm{Ca} 2+$ binding EF-hand motifs ${ }^{[27,29,30]}$. Calcineurin B is encoded by two distinct gene- calcineurin B1 and calcineurin $\mathrm{B} 2^{[31,32]}$.

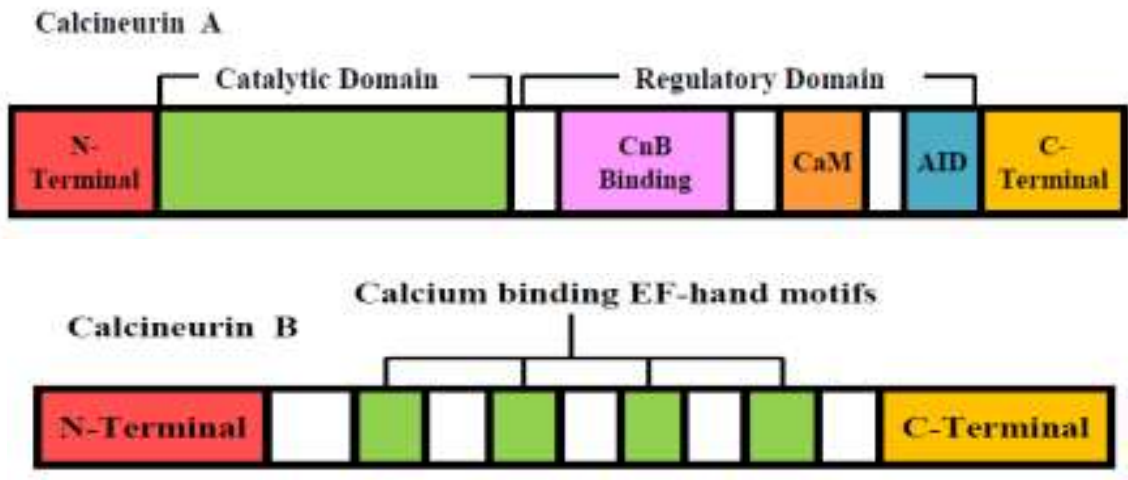

Figure-3: Calcineurin A and Calcineurin B

In the unactivted cells phosphatase activity of calcineurin is inhibited by auto inhibitory domain by interacting with catalytic cleft ${ }^{[33,34]}$. In the activated cell, elevated calcium concentration stimulates the calmodulin which replaces the auto inhibitory domain in the catalytic domain. This results in binding of $\mathrm{CnB}$ to $\mathrm{CnA}$ and activation of calcineurin ${ }^{[33,34]}$. The activated calcineurin dephosphorylates NFAT present in the cytoplasm and dephosphorylated NFAT translocates to the nucleus ${ }^{[33-36]}$. NFAT is the substrate for calcineurin ${ }^{[33,37]}$.

Nuclear factor of activated T cells (NFAT) is a transcription factor which is involved in differentiation of adipocyte, expression of cytokine gene and cardiac hypertrophy ${ }^{[38-40]}$. Five genes (NFATc1, NFATc2, NFATc3, NFATc4 and NFATc5) encoding NFAT protein were identified and named as NFATc1 (NFATc/NFAT2), NFATc2 (NFATp/NFAT1), NFATc3 (NFAT4/NFATx), NFATc4 (NFAT3) and NFAT5 (Ton EBP) ${ }^{[41-45]}$. 


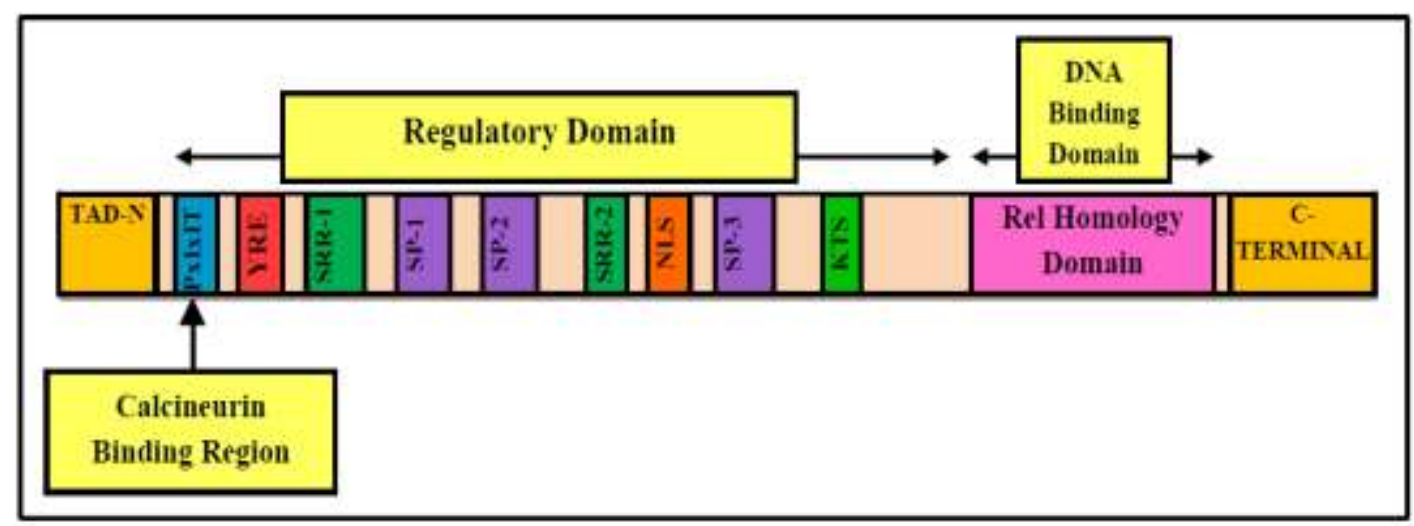

Figure-4: Calcineurin binding region and DNA binding region in NFAT

NFAT structure contains regulatory NFAT homology domain at NH2 terminal which is conserved and DNA binding domain of rel homology family of transcription factor at $\mathrm{COOH}$ terminal ${ }^{[42,46,47]}$. Regulatory domain contains 300 amino acids and in a single exon this regulatory domain is encoded ${ }^{[48]}$. Trans activation domain (TAD) is present at $\mathrm{NH} 2$ terminal and regulatory domain contains calcineurin binding region, serine rich motifs and nuclear localization sequence (NLS) ${ }^{[30]}$. The regulatory NFAT homology domain at $\mathrm{NH} 2$ terminal contains PXIXIT motifs, serine rich region (SRR) and serine-proline (SP) motifs ${ }^{[41,42]}$. These sequences were observed in all members of NFAT. Calcineurin activates NFATc1, NFATc2, NFATc3 and NFATc4. NFAT-3 is expressed in heart and other NFAT are expressed in T cells and skeletal muscle ${ }^{[40]}$. Nuclear translocation of NFAT-3 depends on the activation by calcineurin ${ }^{[49]}$. NFAT-3 activity is regulated by $\mathrm{Ca} 2+$ and calcineurin (Figure-4).

In normal resting cells NFAT proteins are phosphorylated and present in cytoplasm. Regulatory domain contains conserved serine rich motifs (SRR-1,SRR-2,SPxx repeats and KTS) which contains phosphorylated serine ${ }^{[46,50]}$. Three SPxx motifs (serine proline repeat motifs) is present in NFAT, they are designated as SP-1, SP-2 and SP-3 with sequence

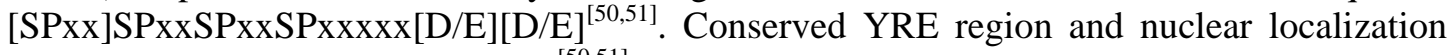
sequence (NLS) is present in NFAT ${ }^{[50,51]}$.

Calcineurin activates NFAT-3 by dephosphorylation and this dephophorylated NFAT-3 translocate to nucleus and binds to target sequence. In nucleus NFAT-3 in synergy with GATA-4 transcription factors cause reprogramming of fetal genes ${ }^{[4,52]}$. Calcineurin phosphatase recognize conserved region which is present in regulatory domain at NH2 terminal of NFAT and dephosphorylates the three serine rich motifs in NFAT ${ }^{[49,53,54]}$. Dephosphorylated NFAT translocates to nucleus and binds to the target sequence in DNA $^{[55,56]}$. Low concentration of activated calcineurin can dephosphorylate serine residues in SRR-1 region. SRR-1 region is present near to PxIxIT, which is the calcineurin docking region $^{[50,51,56]}$. Calcineurin docking site (PxIxIT) sequence in NFAT1 and NFAT2 is SPRIEIT, NFAT3 sequence is CPSIQIT and NFAT4 sequence is CPSIRT. In all NFAT proteins PxIxIT motif are polar ${ }^{[51]}$.

In nucleus NFAT-3 binds to target region and activates the transcription factors and hypertrophic genes expression which results cardiac hypertrophy ${ }^{[57]}$. Inducible phosphorylation site which is located in TAD (Trans Activation Domain) plays an major role in the transcription activity ${ }^{[50]}$. In cardiac hypertrophy fetal gene reprogramming takes place. 
Brain natriuretic peptide (BNP), atrial natriuretic factor (ANF) and $\beta$-myosin heavy chain ( $\beta$ MHC) are expressed in hypertrophised heart ${ }^{[58,59]}$.

\section{Reprogramming and Expression of Fetal Genes by NFAT-3 and GATA-4 Transcription Factors}

In adult myocardium, hypertrophic stimulus cause reprogramming and re-expression of fetal genes ${ }^{[40,60]}$. Fetal genes like atrial natriuretic peptide (ANP), B-type natriuretic peptide (BNP), $\beta$-myosin heavy chain $(\beta$-MHC) and $\alpha$-skeletal actin $(\alpha$-SKA) are upregulated in cardiac hypertrophy. Adult cardiac genes like $\alpha$-MHC, $\alpha$-cardiac actin, sarco/endoplasmic reticulum $\mathrm{Ca} 2+$ ATPase (SERCA) and phospholamban are down regulated during cardiac hypertrophy ${ }^{[40,60]}$.

At carboxyl terminal end NFAT3 contains rel homology domain (RHD) that mediates the DNA binding as monomer or dimer at consensus DNA binding sequence 5'-GGAAAAT$3^{\text {, }}{ }^{[0,61]}$. NFAT3 trans activate BNP in synergy with GATA4. The BNP promoter is a direct transcriptional target for the transcription factors NFAT-3 and GATA-4. In the presence of GATA-4, NFAT-3, and calcineurin, the BNP promoter was activated by over 100 -fold ${ }^{[40]}$. In BNP promoter binding site for NFAT3 was located at -927 site ${ }^{[40,59,62,63]}$. The expression of the (BNP) gene is rapidly elevated in the infracted heart, and plasma BNP levels indicate the degree of left ventricular dysfunction and hypertrophy ${ }^{[64,65]}$.

GATA transcription factors (GATA-1-6) are a class of double zinc finger transcription factors (CysX2-CysX17-CysX2-Cys) that selectively bind to the $(\mathrm{A} / \mathrm{T}) \mathrm{GATA}(\mathrm{A} / \mathrm{G})$ consensus DNA binding sequence ${ }^{[61]}$. GATA-4, 5, 6 is expressed in heart. GATA-4 interacts with transcription factors like MEF-2, NFAT, Nkx-2.5, SRF, dHAND, and YY1 with C-terminal zinc finger domain ${ }^{[61]}$. The N-terminal domain of GATA-4 activity is controlled by numerous signaling pathways as a result of hypertrophic stimulation and is implicated in cardiac hypertrophy development ${ }^{[61]}$.

Atrial natriuretic peptide, B-type natriuretic peptide and C-type natriuretic peptide are the three types of mammalian natriuretic peptides. Both ANP and BNP are expressed in heart ${ }^{[66]}$. In adult human heart BNP consists of 32 amino acids and synthesized by ventricles of heart. BNP possess diuretic, natriuretic and vasodilator properties ${ }^{[64,65]}$. BNP is made up of three exons separated by two introns that are encoded by a single gene (NPPB). In atrial tissue, BNP-32 is $60 \%$ prominent, while in ventricular tissue, proBNP-108 is $60 \%$ prominent ${ }^{[66,67]}$. After birth, the genes for ANF and BNP are downregulated in the ventricles ${ }^{[58]}$. Their levels rise significantly in the adult mammalian heart during hypertrophy and heart failure. BNP gene expression can be used to assess the progression of hypertrophy ${ }^{[58]}$. In the process of myocyte hypertrophy and cardiac fibrosis, ANP and BNP plays a major role ${ }^{[68]}$.

Atrial natriuretic factor and brain natriuretic peptide are encoded by the genes Nppa and Nppb, which are located next to each other in the vertebrate genome. Both genes are expressed in distinct patterns in the embryonic and fetal stages. Expression of Nppa and Nppb in ventricular myocardium is reported in certain cardiovascular failure ${ }^{[69]}$. The ventricles are the major source of BNP expression in the embryonic mouse heart, which peaks at midgestation $(\mathrm{E} 12.5)^{[70]}$. In human foetuses aged 12-17 weeks, no BNP mRNA nor BNP peptide were found ${ }^{[71,72]}$. The level of BNP mRNA in the mouse atrium and ventricle increased after birth, but did not reach the mid-gestation level ${ }^{[70]}$.

ANF and BNP level in plasma is elevated after volume overload ${ }^{[73,74]}$. After atrial pacing, ANF and BNP were rapidly secreted, with a peak around 20-30 minutes later ${ }^{[75]}$. In ventricular stimulation ANP and BNP is secreted within 1-5 minutes. These results clearly demonstrate that myocytes respond quickly to stress ${ }^{[76]}$. With the development of hypertrophy and fibrosis, the level of BNP mRNA is increased ${ }^{[77]}$. BNP mRNA was elevated in the 
ventricles of the individuals with chronic volume overload induced by a regurgitant cardiac valve lesion, although ANF mRNA levels were comparable to the control group. BNP gene expression can be used to track the course of hypertrophy ${ }^{[78]}$.

BNP and NT-proBNP were elevated in the individuals with congenital heart defects like systemic right ventricle and univentricular heart ${ }^{[79]}$. In ventricular cardiomyocytes mechanical stress induces the expression of ANF, BNP and skeletal alpha-actin mRNA ${ }^{[80]}$. ANP and BNP expression were dramatically increased after isoproterenol stimulation. In rats with isoproterenol-induced cardiac hypertrophy, DCAE (Dendrobium candidum aqueous extract)dramatically reduced plasma levels of $\mathrm{ANP}$ and $\mathrm{BNP}^{[81]}$. Isoproterenol induced myocardial infarction in rats increases the BNP mRNA in the ventricles after 18 hours $^{[73]}$.

\section{Inhibitors of Calcineurin and NFAT Pathways in Cardiac Hypertrophy}

cGMP-mediated signalling of nitric oxide (NO) and cGMP-dependent protein kinase type I (PKG I) act as a negative regulator of cardiomyocyte hypertrophy. NO-cGMP-PKGI inhibits calcineurin-NFAT mediated hypertrophy by inhibiting the transcriptional activity of NFAT, BNP expression and cell enlargement ${ }^{[82]}$. Cardiomyocyte hypertrophy is suppressed by telmisartan, a type of angiotensin II receptor inhibitor. Telmisartan inhibits the nuclear translocation of NFAT, expression of ANP and BNP and cardiomyocyte apoptosis ${ }^{[83]}$.

Vitexin, a flavone glucoside derived from the leaf of Crataeguspinnatifida Bunge, inhibits $\mathrm{Ca} 2+$ mediated calcineurin-NFATc3 and CaMKII signalling pathways, resulting in prevention of cardiac hypertrophy ${ }^{[84]}$. In cardiomyocyte hypertrophy, SIRT6, a NAD+dependent class III histone deacetylase, has been shown to block NFATc4 dephosphorylation and nuclear translocation ${ }^{[85]}$. Endogenous calcineurin inhibitors include calcineurin-binding protein 1 (CABIN1) and Down's syndrome critical region 1 (DSCR1) ${ }^{[86]}$. NFAT kinases, including protein kinase A (PKA) ${ }^{[87]}$ as glycogen-synthase kinase 3 (GSK3) ${ }^{[88]}$, casein kinase 1 (CK1) ${ }^{[89]}$,dual-specificity tyrosine-phosphorylation regulated kinase1/2(DYRK1 and DYRK2), extra-cellular signal related kinase (ERK), p38, c-JUN kinase (JNK) and CK2(formerly casein kinase II) ${ }^{[90]}$ rephosphorylate NFAT and inactivate NFAT proteins ${ }^{[86]}$.

The activity of calcineurin is inhibited by calcineurin inhibitor (CAIN) or calcineurinbinding $(\mathrm{CABIN})$ proteins ${ }^{[91]}$. Calcineurin interaction with the substrate is blocked by AKAP79 (A-kinase anchoring protein 79) a scaffold protein ${ }^{[92]}$. Calcineurin homologous protein (CHP) inhibits the phosphatase activity of calcineurin ${ }^{[93]}$. Calcineurin signaling is inhibited by modulatory calcineurin interacting proteins (MCIP), MCIP is also known as calcipressin/Dscr1/Rcn1) ${ }^{[94]}$.

Gossypol, a polyphenolic aldehyde found in cotton plants, inhibits the phosphatase activity of calcineurin ${ }^{[95]}$. Phosphatase activity of calcineurin is inhibited by Lie120, a thiazole derivative ${ }^{[96]}$. In cell lysates, PD 144795, a benzothiophene derivative, inhibits enzymatic activity of Calcineurin ${ }^{[97]}$.The enzymatic activity of calcineurin is inhibited by dibefurin, a fungus-derived phenolic compound ${ }^{[98]}$. Dipyridamole, a drug used in the treatment of strokes, prevents the interaction of calcineurin with $\mathrm{NFAT}^{[99]}$.

NFATc dephosphorylation and nuclear translocation are inhibited by NCI3, a pyrazolopyrimidine derivative ${ }^{[100]}$. Microcystin LR, Dibefurin, PD 144795, Endothal Derivatives, Cantharidin, and Metal-Ligating Phosphonates are among the natural and synthetic chemicals that have been found to be strong inhibitors of calcineurin ${ }^{[27]}$. Punicalagin, a compound extracted from the fruit of the Punica granatum plant, inhibits nuclear translocation and DNA binding of NFAT ${ }^{[101]}$. Imperatorin, a furanocumarin isolated from Oppopanax chironium(L.), inhibits NFAT binding to DNA binding ${ }^{[102]}$. Trifluoperazine 
binds to calmodulin, which prevents its interaction with calcineurin ${ }^{[103]}$. The Roc-1, 2 and 3 Rocaglamide derivatives block NFATc1 translocation into the nucleus, which is caused by activation ${ }^{[104]}$. Barbiturates that suppress phosphatase activity of calcineurin include thiopental, pentobarbital, thiamylal, and secobarbital ${ }^{[105]}$.

\section{Conclusion}

G-Protein coupled receptor activation by isoproterenol increases the calcium level. Elevated calcium activates phosphatase activity of calcineurin. Active form of calcineurin dephosphorylates NFAT-3 in cytoplasm and this result in NFAT-3 nuclear translocation. In nucleus NFAT-3 in synergy with GATA-4 transcription factor reprograms the expression of fetal genes and hypertrophic genes, this result in cardiac hypertrophy. Calcineurin inhibitors like CsA, FK506, Cabin 1/Cain, AKAP79, CHP, MCIP/calcipressin inhibits the activity of calcineurin. Glycogen synthase kinase-3 $\beta$, protein kinase A, MAP kinase, casein kinase 1, cJun N-terminal kinase are involved in rephosphorylation of NFAT and nuclear export ${ }^{[00]}$. Dibefurin, norcantharidin, gossypol, thiopental and tarcolimus blocks the enzymatic activity of calcineurin. Trifluoroperazine prevents binding of $\mathrm{CaM}$ to calcineurin. Dipyridamole prevents binding of calcineurin to NFAT. BTP1 prevents NFAT dephosphorylation. BTP2 reduces calcium influx into cytoplasm ${ }^{[86,106]}$. In future phosphorylation and dephosphorylation sites in NFAT3 can be studied in detail, some of the natural plant based bioactive compounds targeting to block the calcineurin and NFAT activity can be identified to prevent cardiac hypertrophy.

\section{Conflicts of interest statement}

The authors declare no conflicts of interest.

\section{References}

1. Nag AC, Study of non-muscle cells of the adult mammalian heart: a fine structural analysis and distribution. Cytobios 1980;28(109):41-61.

2. Sandier H, Dodge HT. Left Ventricular Tension and Stress in Man. Circ Res 1963;13:91-104.

3. Hood WP, Rackley CE, Rolett EL. Wall stress in the normal and hypertrophied human left ventricle. Am J Cardiol 1968;22(4):550-558.

4. Grossman W, Jones D, McLaurin LP. Wall stress and patterns of hypertrophy in the human left ventricle. J Clin Invest 1975;56(1):56-64.

5. Frey N, Katus HA, Olson EN, Hill JA. Hypertrophy of the Heart: A New Therapeutic Target? Circulation 2004;109(13):1580-9.

6. Bernardo BC, Weeks KL, Pretorius L, McMullen JR. Molecular distinction between physiological and pathological cardiac hypertrophy: Experimental findings and therapeutic strategies. Pharmacol Ther 2010;128(1):191-227.

7. Nagoshi T, Yoshimura M, Rosano GM, Lopaschuk GD, Mochizuki S. Optimization of cardiac metabolism in heart failure. Curr Pharm Des 2011 Dec;17(35):3846-53. 
8. Zhang T, Miyamoto S, Brown JH. Cardiomyocyte calcium and calcium/calmodulindependent protein kinase II: Friends or foes? Recent Prog Horm Res 2004;59:141168.

9. Frey N, McKinsey TA, Olson EN. Decoding calcium signals involved in cardiac growth and function. Nat Med 2000;6(11):1221-1227.

10. Berridge MJ, Bootman MD, Lipp P. Calcium - A life and death signal. Nature 1998;395(6703):645-648.

11. Means AR, VanBerkum MF, Bagchi I, Lu KP, Rasmussen CD. Regulatory functions of calmodulin. Pharmacol Ther 1991;50(2):255-70.

12. Gruver CL, DeMayo F, Goldstein MA, Means AR. Targeted Developmental Overexpression of Calmodulin Induces Proliferative and Hypertrophic Growth of Cardiomyocytes in Transgenic Mice. Endocrinology 1993;133(1):376-88.

13. Sugden PH. Signalling pathways in cardiac myocyte hypertrophy. Ann Med 2001;33(9):611-622.

14. Basith S, Cui M, Macalino SJY, Park J, Clavio NAB, Kang S, et al. Exploring G protein-coupled receptors (GPCRs) ligand space via cheminformatics approaches: Impact on rational drug design. Front Pharmacol 2018;9:1-26.

15. Rockman HA, Koch WJ, Lefkowitz RJ. Seven-transmembrane-spanning receptors and heart function. Nature 2002;415(6868):206-212.

16. Woo AYH, Xiao RP. $\beta$-Adrenergic receptor subtype signaling in heart: From bench to bedside. Acta Pharmacol Sin 2012;33(3):335-41.

17. Chen YJ, Bache RJ. Adenosine: A Modulator of the Cardiac Response to Stress. Circ Res 2003;93(8):691-693.

18. Wieland T, Mittmann C. Regulators of G-protein signalling: Multifunctional proteins with impact on signalling in the cardiovascular system. Pharmacol Ther 2003;97(2):95-115.

19. Rogers JH, Tamirisa P, Kovacs A, Weinheimer C, Courtois M, Blumer KJ, et al. RGS4 causes increased mortality and reduced cardiac hypertrophy in response to pressure overload. J Clin Invest 1999;104(5):567-576.

20. Morisco C, Zebrowski DC, Vatner DE, Vatner SF, Sadoshima J. $\beta$-Adrenergic Cardiac Hypertrophy Is Mediated Primarily By the $\beta 1$-Subtype in the Rat Heart. J Mol Cell Cardiol 2001;33(3):561-573.

21. Berthiaume JM, Kirk JA, Ranek MJ, Lyon RC, Sheikh F, Jensen BC, et al. In: Cardiovascular Pathology. 4th ed. Elsevier Inc.; 2016,p 271-339 .

22. Zou Y, Komuro I, Yamazaki T, Kudoh S, Uozumi H, Kadowaki T, et al. Both G(s) and $\mathrm{G}(\mathrm{i})$ proteins are critically involved in isoproterenol- induced cardiomyocyte hypertrophy. J Biol Chem 1999;274(14):9760-9770.

23. Lohse MJ, Engelhardt S, Eschenhagen T. What Is the Role of $\beta$-Adrenergic Signaling 
in Heart Failure? Circ Res 2003;93(10):896-906.

24. Balakumar P, Jagadeesh G. Multifarious molecular signaling cascades of cardiac hypertrophy: Can the muddy waters be cleared? Pharmacol Res 2010;62(5):365-383.

25. Melaku L, Desalegn T. Molecular mediators, characterization of signaling pathways with descriptions of cellular distinctions in pathophysiology of cardiac hypertrophy and molecular changes underlying a transition toheart failure. Int $J$ Heal Allied Sci 2019;8(1):1-24.

26. Chang CD, Mukai H, Kuno T, Tanaka C. cDNA cloning of an alternatively spliced isoform of the regulatory subunit of $\mathrm{Ca} 2+/$ calmodulin-dependent protein phosphatase (calcineurin B $\alpha 2$ ). Biochim Biophys Acta 1994;1217(2):174-180.

27. Rusnak F, Mertz P. Calcineurin : Form and Function. Physiol Rev 2000;80(4):14831521.

28. Schulz RA, Yutzey KE. Calcineurin signaling and NFAT activation in cardiovascular and skeletal muscle development. Dev Biol 2004;266(1):1-16.

29. Shou J, Jing J, Xie J, You L, Jing Z, Yao J, et al. Nuclear factor of activated T cells in cancer development and treatment. Cancer Lett 2015;361(2):174-84.

30. Di Sole F, Vadnagara K, Moe OW, Babich V. Calcineurin homologous protein: A multifunctional Ca2+-binding protein family. Am $J$ Physiol Ren Physiol 2012;303(2):165-79.

31. Ueki K, Muramatsu T, Kincaid RL. Structure and expression of two isoforms of the murine calmodulin-dependent protein phosphatase regulatory subunit (calcineurin B). Biochem Biophys Res Commun 1992;187(1):537-543.

32. Wilkins BJ, Molkentin JD. Calcium-calcineurin signaling in the regulation of cardiac hypertrophy. Biochem Biophys Res Commun 2004;322(4):1178-91.

33. Medyouf H, Ghysdael J. The calcineurin/NFAT signaling pathway: A novel therapeutic target in leukemia and solid tumors. Cell Cycle 2008;7(3):297-303.

34. Takeuchi K, Roehrl MHA, Sun ZYJ, Wagner G. Structure of the Calcineurin-NFAT Complex: Defining a T Cell Activation Switch Using Solution NMR and Crystal Coordinates. Structure 2007;15(5):587-97.

35. Zarain-Herzberg A, Fragoso-Medina J, Estrada-Aviles R. Calcium-regulated transcriptional pathways in the normal and pathologic heart. IUBMB Life 2011;63(10):847-855.

36. Beals CR, Clipstone NA, Ho SN, Crabtree GR. Nuclear localization of NF-ATc by a calcineurin-dependent, cyclosporin- sensitive intramolecular interaction. Genes Dev 1997;11(7):824-34.

37. Creamer TP. Calcineurin. Cell Commun Signal 2020;18(1):1-12.

38. Yang TTC, Xiong Q, Enslen H, Davis RJ, Chow C-W. Phosphorylation of NFATc4 by p38 Mitogen-Activated Protein Kinases. Mol Cell Biol 2002;22(11):3892-3904. 
39. Ho IC, Kim JHJ, Rooney JW, Spiegelman BM, Glimcher LH. A potential role for the nuclear factor of activated $\mathrm{T}$ cells family of transcriptional regulatory proteins in adipogenesis. Proc Natl Acad Sci USA 1998;95(26):15537-15541.

40. Molkentin JD, Lu JR, Antos CL, Markham B, Richardson J, Robbins J, et al. A calcineurin-dependent transcriptional pathway for cardiac hypertrophy. Cell 1998;93(2):215-228.

41. Buchholz M, Ellenrieder V. An emerging role for Ca2+/calcineurin/NFAT signaling in cancerogenesis. Cell Cycle 2007;6(1):16-19.

42. Rao A, Luo C, Hogan PG. Transcription factors of the NFAT family: Regulation and function. Annu Rev Immunol 1997;15:707-747.

43. Frey N, Olson EN. Cardiac Hypertrophy: The Good, the Bad, and the Ugly. Annu Rev Physiol 2003;65:45-79.

44. Gabriel CH, Gross F, Karl M, Stephanowitz H, Hennig AF, Weber M, et al. Identification of novel nuclear factor of activated T cell (NFAT)-associated proteins in T cells. J Biol Chem 2016;291(46):24172-87.

45. Kiani A, Rao A, Aramburu J. Manipulating immune responses with immunosuppressive agents that target NFAT. Immunity 2000;12:359-372.

46. Monticelli S, Rao A. NFAT1 and NFAT2 are positive regulators of IL-4 gene transcription. Eur J Immunol 2002;32(10):2971-2978.

47. Park J, Takeuchi A, Sharma S. Characterization of a new isoform of the NFAT (nuclear factor of activated T cells) gene family member NFATc. $J$ Biol Chem 1996;271(34):20914-20921.

48. Graef IA, Gastier JM, Francke U, Crabtree GR. Evolutionary relationships among rel domains indicate functional diversification by recombination. Proc Natl Acad Sci USA 2001;98(10):5740-5745.

49. Hogan PG, Chen L, Nardone J, Rao A. Transcriptional regulation by calcium, calcineurin, and NFAT. Genes Dev 2003;17(18):2205-2232.

50. Okamura H, Aramburu J, Garcia-Rodriguez C, Viola JPB, Raghavan A, Tahiliani M, et al. Concerted dephosphorylation of the transcription factor NFAT1 induces a conformational switch that regulates transcriptional activity. Mol Cell 2000;6(3):539550 .

51. Macian F, Lopez-Rodriguez C, Rao A. Partners in transcription: NFAT and AP-1. Oncogene 2001;20(19):2476-2489.

52. Molkentin JD. Calcineurin-NFAT signaling regulates the cardiac hypertrophic response in coordination with the MAPKs. Cardiovasc Res 2004;63(3):467-475.

53. Aramburu J, Garcia-Cozar F, Raghavan A, Okamura H, Rao A, Hogan PG. Selective inhibition of NFAT activation by a peptide spanning the calcineurin targeting site of NFAT. Mol Cell 1998;1(5):627-637. 
54. Chow CW, Rincon M, Davis RJ. Requirement for Transcription Factor NFAT in Interleukin-2 Expression. Mol Cell Biol 1999;19(3):2300-2307.

55. Shaw KT, Ho AM, Raghavan A, Kim J, Jain J, Park J, et al. Immunosuppressive drugs prevent a rapid dephosphorylation of transcription factor NFAT1 in stimulated immune cells. Proc Natl Acad Sci USA 1995;92(24):11205-11209.

56. Li H, Rao A, Hogan PG. Interaction of calcineurin with substrates and targeting proteins. Trends Cell Biol 2011;21(2):91-103.

57. Akazawa H, Komuro I. Roles of cardiac transcription factors in cardiac hypertrophy. Circ Res 2003;92(10):1079-88.

58. Sergeeva IA, Christoffels VM. Regulation of expression of atrial and brain natriuretic peptide, biomarkers for heart development and disease. Biochim Biophys Acta 2013;1832(12):2403-2413.

59. Kuwahara K, Nishikimi T, Nakao K. Transcriptional regulation of the fetal cardiac gene program. J Pharmacol Sci 2012;119(3):198-203.

60. Komuro I, Yazaki Y. Control of cardiac gene expression by mechanical stress. Annu Rev Physiol 1993;55:55-75.

61. Kohli S, Ahuja S, Rani V. Transcription Factors in Heart: Promising Therapeutic Targets in Cardiac Hypertrophy. Curr Cardiol Rev 2012;7(4):262-71.

62. Grepin C, Dagnino L, Robitaille L, Haberstroh L, Antakly T, Nemer M. A hormoneencoding gene identifies a pathway for cardiac but not skeletal muscle gene transcription. Mol Cell Biol 1994;14(5):3115-3129.

63. LaPointe MC. Molecular regulation of the brain natriuretic peptide gene. Peptides 2005;26(6):944-956.

64. He Q, Wang D, Yang XP, Carretero OA, LaPointe MC. Inducible regulation of human brain natriuretic peptide promoter in transgenic mice. Am J Physiol Heart Circ Physiol. 2001;280(1 49-1):368-376.

65. Mukoyama M, Nakao K, Hosoda K, Suga S, Saito Y, Ogawa Y, et al. Brain natriuretic peptide as a novel cardiac hormone in humans: Evidence for an exquisite dual natriuretic peptide system, atrial natriuretic peptide and brain natriuretic peptide. $J$ Clin Invest 1991;87(4):1402-1412.

66. Nishikimi T, Kuwahara K, Nakao K. Current biochemistry, molecular biology, and clinical relevance of natriuretic peptides. J Cardiol 2011;57(2):131-140.

67. Fu S, Ping P, Wang F, Luo L. Synthesis, secretion, function, metabolism and application of natriuretic peptides in heart failure. J Biol Eng 2018;12(1):1-21.

68. Ellmers LJ, Knowles JW, Kim HS, Smithies O, Maeda N, Cameron VA. Ventricular expression of natriuretic peptides in $\mathrm{Npr1}(-/-)$ mice with cardiac hypertrophy and fibrosis. Am J Physiol Heart Circ Physiol 2002;283(2):1-17.

69. Man J, Barnett P, Christoffels VM. Structure and function of the Nppa-Nppb cluster 
locus during heart development and disease. Cell Mol Life Sci 2018;75(8):1435-1444.

70. Cameron VA, Aitken GD, Ellmers LJ, Kennedy MA, Espiner EA. The sites of gene expression of atrial, brain, and C-type natriuretic peptides in mouse fetal development: temporal changes in embryos and placenta. Endocrinology 1996;137(3):817-24.

71. Takahashi T, Allen PD, Izumo S. Expression of A-, B-, and C-type natriuretic peptide genes in failing and developing human ventricles: Correlation with expression of the Ca2+-ATPase gene. Circ Res 1992;71(1):9-17.

72. Pucci A, Wharton J, Arbustini E, Grasso M, Diegoli M, Needleman P, et al. Localization of brain and atrial natriuretic peptide in human and porcine heart. Int $J$ Cardiol 1992;34(3):237-247.

73. Shimoike H, Iwai N, Kinoshita M. Differential regulation of natriuretic peptide genes in infarcted rat hearts. Clin Exp Pharmacol Physiol 1997;24(1):23-30.

74. Leskinen H, Vuolteenaho O, Leppaluoto J, Ruskoaho H. Role of nitric oxide on cardiac hormone secretion: effect of NG-nitro-L-arginine methyl ester on atrial natriuretic peptide and brain natriuretic peptide release. Endocrinology 1995;136(3):1241-1249.

75. Bruneau BG, De Bold AJ. Selective changes in natriuretic peptide and early response gene expression in isolated rat atria following stimulation by stretch or endothelin-1. Cardiovasc Res 1994;28(10):1519-1525.

76. Kinnunen P, Vuolteenaho O, Ruskoaho H. Mechanisms of atrial and brain natriuretic peptide release from rat ventricular myocardium: effect of stretching. Endocrinology 1993;132(5):1961-1970.

77. Sakata Y, Yamamoto K, Masuyama T, Mano T, Nishikawa N, Kuzuya T, et al. Ventricular production of natriuretic peptides and ventricular structural remodeling in hypertensive heart failure. J Hypertens 2001;19(10):1905-1912.

78. Dzimiri N, Moorji A, Afrane B, Al-Halees Z. Differential regulation of atrial and brain natriuretic peptides and its implications for the management of left ventricular volume overload. Eur J Clin Invest. 2002;32(8):563-569.

79. Eindhoven JA, Van Den Bosch AE, Jansen PR, Boersma E, Roos-Hesselink JW. The Usefulness of brain natriuretic peptide in complex congenital heart disease: A systematic review. J Am Coll Cardiol 2012;60(21):2140-2149.

80. Pikkarainen S, Tokola H, Majalahti-Palviainen T, Kerkela R, Hautala N, Bhalla SS, et al. GATA-4 is a nuclear mediator of mechanical stretch-activated hypertrophic program. J Biol Chem. 2003;278(26):23807-16.

81. Cao YY, Li K, Li Y, Tian XT, Ba HX, Wang A, et al. Dendrobium candidum aqueous extract attenuates isoproterenol-induced cardiac hypertrophy through the ERK signalling pathway. Pharm Biol 2020;58(1):176-183.

82. Fiedler B, Lohmann SM, Smolenski A, Linnemuller S, Pieske B, Schroder F, et al. Inhibition of calcineurin-NFAT hypertrophy signaling by cGMP-dependent protein 
kinase type I in cardiac myocytes. Proc Natl Acad Sci USA 2002;99(17):1136311368.

83. Li X, Lan Y, Wang Y, Nie M, Lu Y, Zhao E. Telmisartan suppresses cardiac hypertrophy by inhibiting cardiomyocyte apoptosis via the NFAT/ANP/BNP signaling pathway. Mol Med Rep 2017;15(5):2574-2582.

84. Lu CC, Xu YQ, Wu JC, Hang PZ, Wang Y, Wang C, et al. Vitexin protects against cardiac hypertrophy via inhibiting calcineurin and CaMKII signaling pathways. Naunyn Schmiedebergs Arch Pharmacol. 2013;386(8):747-755.

85. Li Z, Zhang X, Guo Z, Zhong Y, Wang P, Li J, et al. SIRT6 suppresses NFATc4 expression and activation in cardiomyocyte hypertrophy. Front Pharmacol 2019;9:114.

86. Qin JJ, Nag S, Wang W, Zhou J, Zhang WD, Wang H, et al. NFAT as cancer target: Mission possible? Biochim Biophys Acta 2014;1846(2):297-311.

87. Gwack Y, Sharma S, Nardone J, Tanasa B, Iuga A, Srikanth S, et al. A genome-wide Drosophila RNAi screen identifies DYRK-family kinases as regulators of NFAT. Nature 2006;441(7093):646-650.

88. Beals CR, Sheridan CM, Turck CW, Gardner P, Crabtree GR. Nuclear export of NFATc enhanced by glycogen synthase kinase-3. Science 1997;275(5308):1930-1933.

89. Okamura H, Garcia-Rodriguez C, Martinson H, Qin J, Virshup DM, Rao A. A Conserved Docking Motif for CK1 Binding Controls the Nuclear Localization of NFAT1. Mol Cell Biol 2004;24(10):4184-4195.

90. Porter CM, Havens MA, Clipstone NA. Identification of amino acid residues and protein kinases involved in the regulation of NFATc subcellular localization. $J$ Biol Chem 2000;275(5):3543-3551.

91. Lai MM, Burnett PE, Wolosker H, Blackshaw S, Snyder SH. Cain, a novel physiologic protein inhibitor of calcineurin. J Biol Chem 1998;273(29):18325-18331.

92. Kipanyula MJ, Kimaro WH, Etet PFS. The Emerging Roles of the CalcineurinNuclear Factor of Activated T-Lymphocytes Pathway in Nervous System Functions and Diseases. J Aging Res 2016;2016:1-20.

93. Lin X, Sikkink RA, Rusnak F, Barber DL. Inhibition of calcineurin phosphatase activity by a calcineurin B homologous protein. J Biol Chem 1999;274(51):3612536131.

94. Aramburu J, Heitman J, Crabtree GR. Calcineurin: A central controller of signalling in eukaryotes. Workshop on the calcium/calcineurin/NFAT pathway: Regulation and function. EMBO Rep 2004;5(4):343-8.

95. Carruthers NJ, Dowd MK, Stemmer PM. Gossypol inhibits calcineurin phosphatase activity at multiple sites. Eur J Pharmacol 2007;555(2-3):106-114.

96. Klettner A, Baumgrass R, Zhang Y, Fischer G, Burger E, Herdegen T, et al. The neuroprotective actions of FK506 binding protein ligands: Neuronal survival is 
triggered by de novo RNA synthesis, but is independent of inhibition of JNK and calcineurin. Mol Brain Res 2001;97(1):21-31.

97. Gualberto A, Marquez G, Carballo M, Youngblood GL, Hunt SW, Baldwin AS, et al. p53 transactivation of the HIV-1 long terminal repeat is blocked by PD 144795, a calcineurin-inhibitor with anti-HIV properties. J Biol Chem. 1998;273(12):7088-7093.

98. Brill GM, Premachandran U, Karwowski JP, Henry R, Cwik DK, Traphagen LM, et al. Dibefurin, a novel fungal metabolite inhibiting calcineurin phosphatase activity. J Antibiot (Tokyo) 1996;49(2):124-128.

99. Mulero MC, Aubareda A, Orzaez A, Messeguer J, Serrano-Candelas E, MartínezHoyer S, et al. Inhibiting the calcineurin-NFAT (nuclear factor of activated T cells) signaling pathway with a regulator of calcineurin-derived peptide without affecting general calcineurin phosphatase activity. J Biol Chem 2009;284(14):9394-9401.

100. Sieber M, Karanik M, Brandt C, Blex C, Podtschaske M, Erdmann F, et al. Inhibition of calcineurin-NFAT signalling by the pyrazolopyrimidine compound NC13. Eur J Immunol 2007;37(9):2617-2626.

101. Lee SI, Kim BS, Kim KS, Lee S, Shin KS, Lim JS. Immune-suppressive activity of punicalagin via inhibition of NFAT activation. Biochem Biophys Res Commun 2008;371(4):799-803.

102. Marquez N, Sancho R, Ballero M, Bremner P, Appendino G, Fiebich BL, et al. Imperatorin inhibits $\mathrm{T}$-cell proliferation by targeting the transcription factor NFAT. Planta Med. 2004;70(11):1016-1021.

103. Yang S Der, Tallant EA, Cheung WY. Calcineurin is a calmodulin-dependent protein phosphatase. Biochem Biophys Res Commun. 1982;106(4):1419-1425.

104. Proksch P, Giaisi M, Treiber MK, Palfi K, Merling A, Spring H, et al. Rocaglamide derivatives are immunosuppressive phytochemicals that target NF-AT Activity in T Cells. J Immunol. 2005;174(11):7075-7084.

105. Humar M, Pischke SE, Loop T, Hoetzel A, Schmidt R, Klaas C, et al. Barbiturates directly inhibit the calmodulin/calcineurin complex: a novel mechanism of inhibition of nuclear factor of activated T cells. Mol Pharmacol 2004;65(2):350-361.

106. Sieber M, Baumgrass R. Novel inhibitors of the calcineurin/NFATc hub - Alternatives to CsA and FK506? Cell Commun Signal 2009;7(25):1-19. 